\title{
Intervensi Sleep Hygiene pada Anak Usia Sekolah dengan Gangguan Tidur: Sebuah Penelitian Awal
}

Eva Devita Harmoniati, Rini Sekartini, Hartono Gunardi

Departemen Ilmu Kesehatan Anak Fakultas Kedokteran Universitas Indonesia

Latar belakang. Gangguan tidur adalah kondisi yang ditandai dengan gangguan jumlah, kualitas, atau waktu tidur. Dampak gangguan tidur adalah gangguan belajar, memori, mood, perilaku, dan atensi.

Tujuan. Mengetahui prevalensi, gambaran gangguan tidur, pengaruh intervensi sleep hygiene pada keluhan mengantuk, mood, kesulitan bangun, durasi tidur, nilai SDSC dan PDSS.

Metode. Penelitian quasi eksperimental di SDN di Jakarta Pusat pada bulan Mei-Juni 2015. Skrining dan evaluasi pasca intervensi sleep hygiene selama 8 minggu menggunakan sleep disturbance scale for children (SDSC) dan pediatric daytime sleepiness scale (PDSS).

Hasil. Prevalensi gangguan tidur 25,1\%, terdiri atas disorder of initiating and maintaining sleep (DIMS) 61,5\%, sleep wake transition disorder (SWTD) 61,5\%, disorder of excessive somnolence (DOES) 55,4\%, dan disorder of arousal (DA) 51,5\%. Setelah intervensi dilaporkan perbaikan mengantuk, mood, kesulitan bangun pagi, nilai SDSC pre dan pasca intervensi $(\mathrm{p}<0,001)$.

Kesimpulan. Dampak intervensi sleep hygiene yaitu perbaikan mengantuk, mood, kesulitan bangun pagi, serta perbedaan bermakna nilai SDSC pre dan pasca intervensi. Sari Pediatri 2016;18(2):93-9

Kata kunci: gangguan tidur, intervensi, sleep hygiene

\section{Sleep Hygiene Intervention in School-Aged Children with Sleep Disorder: A Preliminary Study}

Eva Devita Harmoniati, Rini Sekartini, Hartono Gunardi

Background. Sleep disorder is a condition characterized by disorder of amount, quality, or duration of sleep. Its impacts are difficulties in learning, memory, mood, behavior, and attention.

Objectives. Evaluate prevalence, description of sleep disorder, impact of intervention on daytime sleepiness, mood, difficulty waking up, duration of sleep, and on Sleep Disturbance Scale for Children (SDSC) and Pediatric Daytime Sleepiness Scale (PDSS) score.

Methods. Quasi experiment study in elementary schools in Central Jakarta during Mei-June 2015. Screening and evaluation after 8 weeks of intervention using SDSC and PDSS scores.

Results. Sleep disorder prevalence was 25.1\%: Disorder of initiating and maintaining sleep (DIMS) 61.5\%, Sleep wake transition disorder (SWTD) 61.5\%, Disorder of excessive somnolence (DOES) 55.4\%, and Disorder of arousal (DA) $51.5 \%$. Improvements in daytime sleepiness, mood, difficulty waking up, pre and post intervention as measured with SDSC score show significant improvements $(\mathrm{p}<0,001)$.

Conclusions. Sleep hygiene intervention shows improvements in daytime sleepiness, mood, difficulty waking up, and significant differences of the SDSC score. Sari Pediatri 2016;18(2):93-9

Key words: intervention, sleep disorder, sleep hygiene

Alamat korespondensi: Dr. Eva Devita Harmoniati, DR. Dr. Rini Sekartini, SpA(K). Departemen Ilmu Kesehatan Anak Fakultas Kedokteran Universitas Indonesia. E-mail: evasuhendar@yahoo.com 


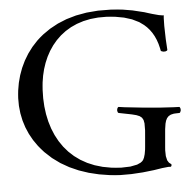

angguan tidur adalah suatu kumpulan kondisi yang ditandai dengan gangguan dalam jumlah, kualitas, atau waktu tidur pada seorang individu. ${ }^{1}$ Gangguan ini merupakan masalah yang umum terjadi pada anak dan remaja dengan prevalensi antara $25 \%-40 \%$. ${ }^{2,3}$ Pada anak usia sekolah, prevalensi gangguan tidur mencapai $30 \% .{ }^{4}$ Anak dengan gangguan tidur yang kronis dapat mengalami gangguan belajar dan memori di sekolah, iritabel, perubahan mood, kesulitan mempertahankan perhatian, dan perubahan perilaku seperti agresif, hiperaktif, atau impulsivitas. ${ }^{1-4}$

Gangguan tidur pada anak dan remaja ditunjukkan dengan jumlah waktu tidur yang tidak adekuat disebabkan oleh kombinasi faktor intrinsik dan ekstrinsik. Faktor intrinsik di antaranya perubahan perkembangan alami, seperti pergeseran irama sirkadian selama pubertas, delayed sleep phase syndrome, dan sleep disordered breathing (SDB), seperti obstructive sleep apnea (OSA). Faktor ekstrinsik yang memengaruhi terjadinya gangguan tidur di antaranya waktu mulai sekolah lebih awal dan kebiasaan sebelum tidur, seperti konsumsi kafein dan penggunaan alat elektronik mendekati waktu tidur. ${ }^{5}$

Beberapa penelitian menunjukkan penerapan kebiasaan menjelang tidur yang baik atau dikenal dengan istilah sleep hygiene merupakan prediktor penting kualitas tidur pada remaja..$^{5-7}$ Namun, penelitian tersebut lebih banyak fokus pada remaja akhir, data tentang penerapannya pada anak usia sekolah masih terbatas. Data mengenai intervensi sleep hygiene pada anak dan remaja di Indonesia belum diketahui.

Tujuan penelitian pada anak usia sekolah ini adalah ingin mengetahui prevalensi gangguan tidur, gambaran gangguan tidur, pengaruh intervensi sleep hygiene pada keluhan mengantuk, mood anak seharihari, kesulitan bangun tidur di pagi hari, jumlah waktu tidur anak setelah diintervensi dengan sleep hygiene serta pengaruhnya terhadap nilai SDSC dan PDSS.

\section{Metode}

Penelitian quasi eksperimental tentang dampak intervensi sleep hygiene selama 8 minggu yang dilakukan pada anak usia sekolah dengan gangguan tidur. Penelitian dilakukan pada bulan Maret-Juni 2015 di Sekolah Dasar Negeri (SDN) 02, 03 Menteng, dan
Gondangdia 01 di Jakarta Pusat.

Kriteria inklusi adalah siswa sekolah dasar negeri di Jakarta Pusat usia 6-12 tahun yang mengembalikan kuesioner skrining gangguan tidur (sleep disturbance scale for children) dan kuesioner pediatric daytime sleepiness scale (PDSS), serta bersedia mengikuti intervensi sleep hygiene selama 8 minggu. Kriteria eksklusi adalah siswa sekolah dasar negeri di Jakarta Pusat dengan data identitas yang tidak lengkap serta tidak mengembalikan kuesioner skrining gangguan tidur serta PDSS atau tidak bersedia mengikuti intervensi sleep hygiene selama 8 minggu.

Dilakukan skrining gangguan tidur pada seluruh siswa SDN 02, 03, dan siswa kelas 1-5 SDN Gondangdia 01 Jakarta menggunakan kuesioner SDSC dan PDSS. Siswa yang memenuhi kriteria gangguan tidur berdasarkan nilai total SDSC dan orangtua menandatangani surat persetujuan, diberikan penjelasan tentang penelitian yang akan dilakukan. Siswa diberikan penjelasan tentang gangguan tidur, rutinitas sleep hygiene, serta prosedur penelitian yang harus dilakukan. Prosedur sleep hygiene yang diajarkan adalah modifikasi dari Program Ferret ${ }^{6}$ yang terdiri atas tidur pada waktu yang sama setiap hari, tidak minum apa pun 30 menit sebelum tidur, tidak menggunakan alat elektronik 30 menit sebelum tidur, meredupkan lampu kamar tidur, tidak mengerjakan PR di tempat tidur, dan membuka jendela atau menyalakan lampu kamar saat bangun tidur. Pada akhir minggu ke-8, siswa yang mengikuti intervensi mengumpulkan catatan harian tidur dan kembali mengisi kuesioner SDSC dan PDSS. Data kemudian diolah menggunakan program SPSS.

\section{Hasil}

Jumlah subyek yang mengembalikan kuesioner yang dibagikan 638, 121 di antaranya dieksklusi karena kuesioner tidak diisi dengan lengkap. Didapat 130 subyek yang memenuhi kriteria gangguan tidur berdasarkan skor SDSC $\geq 46$ yang digunakan pada penelitian ini. Namun, hanya 113 subyek yang mendapat persetujuan orangtua untuk mengikuti intervensi sleep hygiene selama 8 minggu. Pada minggu ke-8 terdapat 30 dari 113 subyek yang mengembalikan kuesioner SDSC dan PDSS. Delapan puluh tiga subjek drop-out karena tidak mengembalikan kuesioner SDSC dan PDSS minggu ke-8. (Gambar 1) 


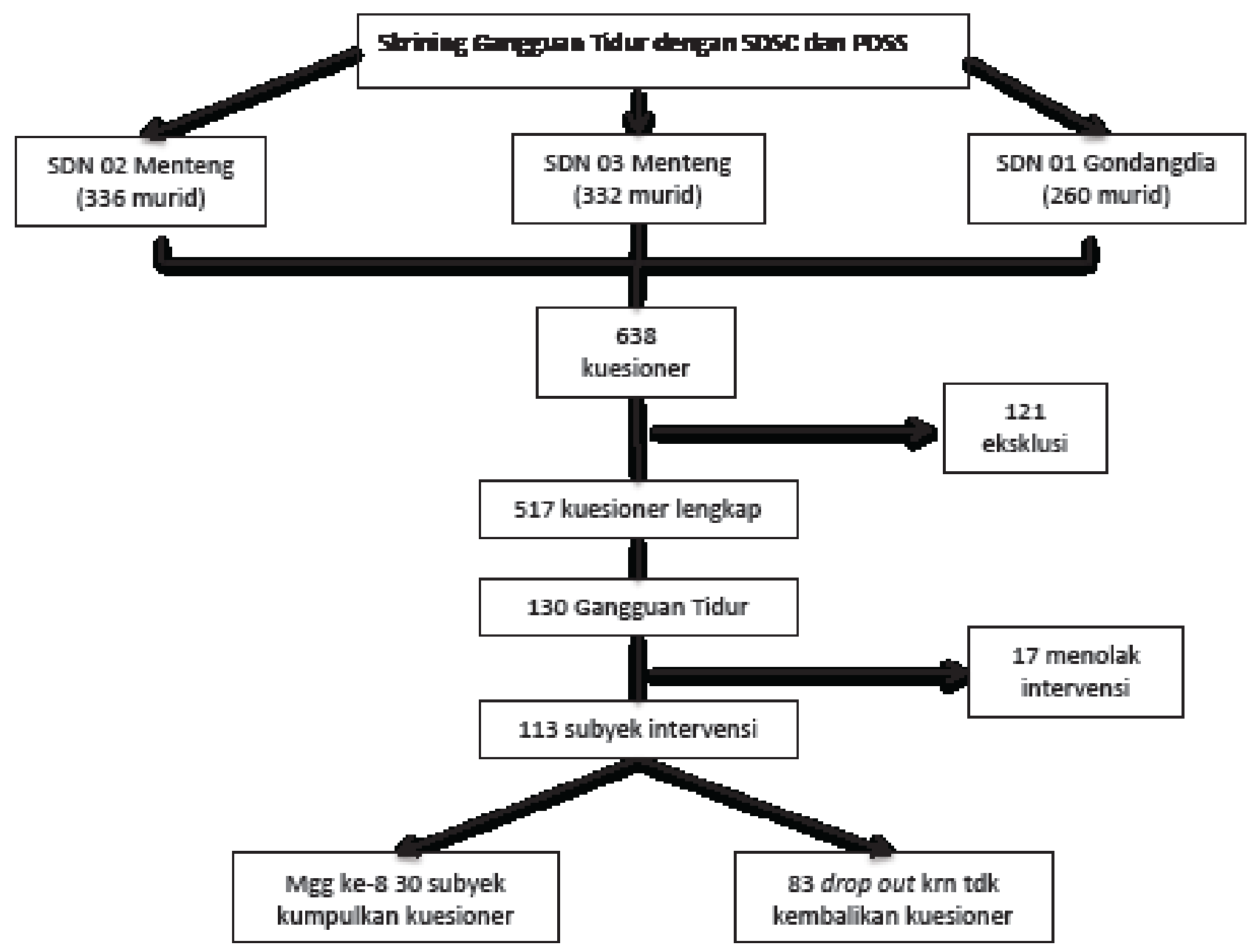

Gambar 1. Alur subyek penelitian

Lama waktu tidur sebagian besar $(68,9 \%)$ subyek kurang dari 9 jam dan hanya $31,1 \%$ yang memiliki jumlah waktu tidur lebih dari 9 jam. Waktu bangun tidur sebagian besar (94\%) juga berkisar antara pukul 05.00-06.00. Hal tersebut disebabkan waktu sekolah yang dimulai pada pukul 06.30 sehingga murid sekolah harus bangun pagi hari agar tidak terlambat masuk ke sekolah. Waktu tidur sebagian subyek adalah pukul 9 malam atau lebih pada hari-hari tidak sekolah (Tabel. 1)

Sebagian subyek $(44,1 \%$ dan $35,2 \%)$ masih tidur bersama orangtua atau saudara. Keberadaan alat elektronik di kamar tidur cukup banyak. Hampir semua subyek memiliki alat elektronik di kamar tidur, sebagian besar $(56,3 \%)$ memiliki 1 alat dan yang lainnya memiliki 2 atau lebih alat elektronik. Kebiasaan sebelum tidur juga memengaruhi kualitas tidur anak secara keseluruhan. Pada penelitian ini, sebagian besar anak menonton TV atau bermain dengan alat elektronik seperti tablet, laptop, atau komputer sebelum tidur $(56,1 \%)$ (Tabel 1).

Prevalensi gangguan tidur pada anak usia sekolah (6-12 tahun) adalah 25,1\%. Subtipe gangguan tidur yang dialami sebagian besar adalah DIMS 61,5\%, SWTD 61,5\%, DOES 55,4\%, dan DA 51,5\%. Penelitian ini juga menunjukkan bahwa satu subyek dapat mengalami lebih dari satu jenis gangguan tidur (Tabel. 2)

Sebelum intervensi, terdapat kejadian keluhan mengantuk di sekolah, cepat marah dan lelah, serta kesulitan bangun tidur di pagi hari yang dialami oleh 
Tabel 1. Karakteristik responden

\begin{tabular}{|c|c|c|}
\hline Karakteristik & $\begin{array}{l}\text { Jumlah } \\
(\mathrm{N}=517)\end{array}$ & $\begin{array}{c}\text { Persentase } \\
(\%)\end{array}$ \\
\hline \multicolumn{3}{|l|}{ Jenis kelamin } \\
\hline Laki-laki & 237 & 45,8 \\
\hline Perempuan & 280 & 54,2 \\
\hline \multicolumn{3}{|l|}{ Usia (tahun) } \\
\hline $6-9$ & 352 & 68,1 \\
\hline $10-12$ & 165 & 31,9 \\
\hline \multicolumn{3}{|l|}{ Pendidikan orangtua } \\
\hline Rendah & 8 & 1,5 \\
\hline Menengah & 157 & 30,4 \\
\hline Tinggi & 352 & 68,1 \\
\hline \multicolumn{3}{|l|}{ Lama waktu tidur (jam) } \\
\hline$<9$ & 355 & 68,9 \\
\hline$\geq 9$ & 161 & 31,1 \\
\hline \multicolumn{3}{|l|}{ Waktu bangun tidur } \\
\hline Jam 05.00-06.00 & 486 & 94 \\
\hline Jam 06.00-07.00 & 30 & 6 \\
\hline \multicolumn{3}{|l|}{ Kamar tidur } \\
\hline Sendiri & 107 & 20,7 \\
\hline Tidur bersama saudara & 182 & 35,2 \\
\hline Tidur bersama orangtua & 228 & 44,1 \\
\hline \multicolumn{3}{|c|}{ Alat elektronik di kamar (TV, HP, laptop, komputer, video) } \\
\hline Tidak ada & 2 & 0,4 \\
\hline 1 alat elektronik & 291 & 56,3 \\
\hline 2 alat elektronik & 141 & 27,3 \\
\hline 3 alat elektronik & 63 & 12,2 \\
\hline 4 alat elektronik & 16 & 3,1 \\
\hline 5 alat elektronik & 4 & 0,8 \\
\hline \multicolumn{3}{|l|}{ Kebiasaan sebelum tidur } \\
\hline Tidak ada & 27 & 5,7 \\
\hline Membaca buku/majalah & 49 & 9,5 \\
\hline Mendengarkan musik & 13 & 2,5 \\
\hline Menonton TV/tablet/laptop/komputer & 290 & 56,1 \\
\hline Mandi/sikat gigi & 87 & 16,8 \\
\hline \multicolumn{3}{|c|}{ Kebiasaan minum soda/teh/coklat sebelum tidur } \\
\hline Ya & 35 & 6,8 \\
\hline Tidak & 482 & 93,2 \\
\hline
\end{tabular}

Tabel 2. Gambaran gangguan tidur pada anak usia sekolah

\begin{tabular}{lcc}
\hline Gangguan tidur & Jumlah & Persentase (\%) \\
\hline Disorder of initiating and maintaining sleep (DIMS) $>14$ & 80 & 61,5 \\
Sleep-disorder breathing $($ SDB) $>5$ & 28 & 21,5 \\
Disorder of arousal $(\mathrm{DA})>3$ & 67 & 51,5 \\
Sleep wake transition disorders (SWTD) $>11$ & 80 & 61,5 \\
Disorder of excessive somnolence (DOES) $>10$ & 72 & 55,4 \\
Sleep hyperhidrosis $(\mathrm{SHY})>4$ & 30 & 23,1 \\
\hline
\end{tabular}

* Satu subyek bisa lebih dari satu subtipe gangguan tidur 
Eva Devita Harmoniati dkk: Intervensi sleep hygiene pada anak usia sekolah dengan gangguan tidur

Tabel 3. Perbedaan nilai total SDSC dan PDSS pre dan pasca intervensi

\begin{tabular}{lccc}
\hline Sleep hygiene & Pre intervensi & Pasca intervensi & $\mathrm{p}$ \\
\hline SDSC (laporan orangtua) & $48(46-74) \#$ & $43,5(26-64) \#$ & $<0,001^{*}$ \\
PDSS & 13,3 (SD 5,3) & 11,2 (SD 4,8) & $0,102^{* *}$ \\
\hline
\end{tabular}

\# median; *Uji Wilcoxon

$\square$ mean; **Uji T Berpasangan

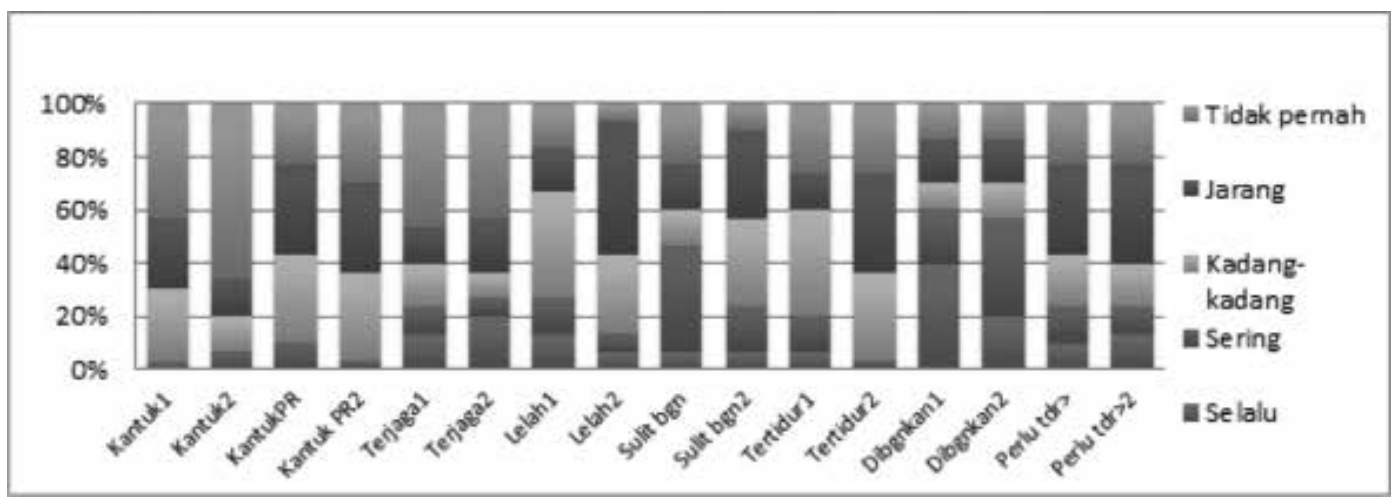

Gambar 2. Grafik nilai PDSS pra dan pasca intervensi

sebagian besar subyek. Setelah intervensi berkurang kejadiannya (Gambar 2).

Terdapat penurunan rerata nilai total SDSC dari sebelum intervensi dan sesudah intervensi, 51,5 menjadi 44,2 dan penurunan median nilai SDSC dari 48 (46-74) menjadi 43,5 (26-64) dengan nilai $\mathrm{p}<0,001$ (Tabel 3). Menunjukkan ada perbedaan yang bermakna pada nilai SDSC subyek setelah menjalani intervensi sleep hygiene selama 8 minggu.

Didapatkan penurunan rerata nilai total PDSS, sebelum intervensi 13,3 menjadi 11,2 dengan nilai $\mathrm{p}=0,102$ (Tabel 3). Menunjukkan penurunan nilai PDSS tidak bermakna setelah intervensi sleep hygiene selama 8 minggu.

\section{Pembahasan}

Keterbatasan penelitian kami adalah jumlah kasus drop out yang melebihi $10 \%$ dari jumlah yang diperkirakan. Hal tersebut disebabkan karena masa ujian nasional, ujian semester, dan libur sekolah yang terjadi selama masa penelitian berlangsung. Kondisi tersebut menyebabkan kesulitan pengumpulan kembali kuesioner untuk evaluasi intervensi. Keterbatasan lainnya adalah kerjasama dan minat orangtua yang kurang terhadap masalah gangguan tidur pada anak.

Prevalensi subyek penelitian yang mengalami gangguan tidur berdasarkan skor total SDSC $\geq 46$ adalah 25,1\% (130 subyek). Subyek laki-laki 58 $(40,8 \%)$ orang dan perempuan $72(55,4 \%)$. Sebagian besar subyek (81 subyek $(62,3 \%)$ ) berusia antara 6-10 tahun dan 49 subyek $(37,7 \%)$ berusia antara 11-12 tahun. Dalam literatur juga ditemukan prevalensi yang sama, gangguan tidur pada anak $25 \% .{ }^{11}$ Penelitian lain mendapatkan prevalensi gangguan tidur yang hampir sama pada anak usia 4,5-16,5 tahun, yaitu sebesar $24,6 \% .^{12}$

Gambaran gangguan tidur yang dialami sebagian besar subyek penelitian adalah DIMS 61,5\%, SWTD 61,5\%, DOES 55,4\%, dan DA 51,5\%. Blunden $\mathrm{dkk}^{13}$ melaporkan bahwa pada anak usia 4,5-16,5 tahun SDB, DOES, SWTD, dan DIMS merupakan subtipe gangguan yang banyak ditemukan. Penelitian lain menemukan gangguan tidur berupa behavioral insomnia sebagai gangguan tidur yang banyak dialami (20\%-30\%) oleh anak dan remaja. ${ }^{11}$ Namun, sedikit berbeda, Spruyt dkk ${ }^{14}$ melaporkan DOES sebagai subtipe yang banyak ditemukan pada anak usia sekolah yang normal. 
Penelitian kami juga menunjukkan bahwa satu subyek dapat mengalami lebih dari satu jenis gangguan tidur. Hal tersebut terjadi karena satu gangguan tidur dapat berkorelasi dengan gangguan tidur lainnya. Beberapa penelitian juga menunjukkan adanya komorbiditas atau koeksistensi antara satu jenis gangguan tidur dengan jenis lainnya, walaupun kekuatan korelasinya rendah sampai sedang. ${ }^{13,14}$ Gangguan tidur yang menunjukkan korelasi yang sedang dengan jenis gangguan tidur lainnya adalah SWTD dan DIMS. ${ }^{13}$

Setelah intervensi sleep hygiene selama 8 minggu, dari kuesioner PDSS didapatkan subyek yang sebelumnya mengalami keluhan mengantuk di sekolah, cepat marah dan lelah, serta kesulitan bangun tidur di pagi hari, berkurang kejadiannya setelah intervensi. Subyek yang sebelum intervensi sering mengalami keluhan tersebut menjadi berkurang setelah intervensi. Namun, berdasarkan perhitungan statistik, tidak menunjukkan perbedaan bermakna pada total nilai PDSS sebelum dan sesudah intervensi. Berkurangnya keluhan ini dapat disebabkan prosedur yang mulai terbiasa dilakukan setiap hari atau karena sudah lebih banyak hari libur sekolah pada minggu ke-8 penelitian. Keterbatasan penelitian kami adalah tidak semua subyek yang menjalani intervensi mengisi catatan harian tidur dengan lengkap sehingga sulit untuk disimpulkan apakah berkurangnya keluhan mengantuk karena prosedur sleep hygiene yang dijalankan atau karena perubahan pola tidur akibat hari libur di sekolah yang lebih banyak.

Berbeda dengan total nilai PDSS, terdapat perbedaan bermakna nilai total SDSC sebelum dan sesudah intervensi. Sesuai dengan hasil penelitian intervensi sleep hygiene dengan program Ferret yang dilakukan pada 33 subyek penelitian pada studi pendahuluan di Selandia Baru. ${ }^{6}$ Penelitian tersebut mendapatkan penurunan nilai SDSC, rerata 53,4 menjadi 39,2 setelah intervensi. Namun, intervensi pada penelitian tersebut berlangsung lebih lama, yaitu selama 20 minggu, sedangkan penelitian kami hanya 8 minggu.

\section{Kesimpulan}

Intervensi sleep hygiene selama 8 minggu pada anak usia sekolah dengan gangguan tidur menunjukkan berkurangnya keluhan mengantuk di sekolah, mood sehari-hari, dan kesulitan bangun di pagi hari. Namun, tidak didapatkan perubahan lama waktu tidur pasca intervensi. Pendidikan tentang pentingnya pola tidur dan kualitas tidur yang baik diperlukan agar anak dapat menerapkan rutinitas yang baik sebelum tidur untuk menjamin kualitas tidur yang baik dan mendapat manfaat optimal dari tidur. Penelitian lanjutan tentang manfaat sleep hygiene pada anak usia sekolah perlu dilakukan dengan lingkup dan jumlah sampel yang lebih besar agar dampaknya terhadap kualitas tidur, fungsi kognitif, dan aktivitas sehari-hari anak dapat dianalisis.

\section{Daftar pustaka}

1. Tanjung MFC, Sekartini R. Masalah tidur pada anak. Sari Pediatri 2004;6:138-42.

2. Waters KA, Suresh S, Nixon GM. Sleep disorders in children. MJA 2013;199:S31-5.

3. Mindell JA, Meltzer LJ, Carskadon MA, Chervin RD. Developmental aspects of sleep hygiene: findings from the 2004 national sleep foundation sleep in America poll. Sleep Medicine 2009;10:771-9.

4. Stein MA, Mendelson J, Obermeyer WH, Amromin J, Benca R. Sleep and behavior problems in school-aged children. Pediatrics 2001;107:e60.

5. Halal CSE, Nunes ML. Education in children's sleep hygiene: which approaches are effective? A systematic review. J Pediatr (Rio J) 2014;90:449-56.

6. Tan E, Healey D, Gray AR, Galland BC. Sleep hygiene intervention for youth aged 10 to 18 years with problematic sleep: a before-after pilot study. BMC Pediatrics 2012;12:189-98.

7. Mindell JA, Meltxer LJ. Behavioral sleep disorders in children and adolescents. Ann Acad Med Singapore 2008;37:722-8

8. El Shakankiry HM. Sleep physiology and sleep disorders in childhood. Nature Sci Sleep 2011;3:101-14.

9. Primhak R, Kingshott R. Sleep physiology and sleepdisordered breathing: the essentials. Arch Dis Child 2012;97:54-8.

10. Chokroverty S. Overview of sleep and sleep disorders. Indian J Med Res 2010;131:126-40.

11. Vriend J, Corkum P. Clinical management of behavioral insomnia of childhood. Psychol Res Behavior Management 2011;4:69-80.

12. Mindell JA, Sadeh A, Wiegand B, How TH, Goh DYT. Cross-cultural difference in infant and toddler sleep. Sleep Medicine 2010;11:274-80 (Abstract). 
Eva Devita Harmoniati dkk: Intervensi sleep hygiene pada anak usia sekolah dengan gangguan tidur

13. Blunden S, Lushington K, Loranzen B, Coi T, Fung F, Kenedy D. Are sleep problems underrecognised in general practice? Arch Dis Child 2004;89:708-12.
14. Spruyt K, O’Brien LM, Cluydts R, Verleye GB, Ferri $\mathrm{R}$. Odds, prevalence and predictors of sleep problems in school-age normal children. J. Sleep Res 2005; 14:163-76. 